\title{
Molecular dynamics and density functional theory study on the corrosion inhibition of austenitic stainless steel in hydrochloric acid by two pyrimidine compounds
}

\author{
Fahimeh Shojaie $^{1} \cdot$ Nasser Mirzai-Baghini $^{2}$
}

Received: 29 January 2015/ Accepted: 20 July 2015/Published online: 7 August 2015

(c) The Author(s) 2015. This article is published with open access at Springerlink.com

\begin{abstract}
Quantum chemical calculations based on density functional theory method were performed on two pyrimidine derivatives which may be used as corrosion inhibitors for austenitic stainless steel. The quantum chemical properties of the two pyrimidine derivatives that are most relevant to their potential action as corrosion inhibitors have been calculated. To explain the inhibition performance of the pyrimidine derivatives, their local reactivities were analyzed through Fukui functions. The binding energies of the inhibitors with the surface of austenitic stainless steels were studied. A model has been suggested to calculate the approximate inhibition efficiencies of the pyrimidine derivatives. All calculations were carried out in both gas and liquid phases.
\end{abstract}

Keywords Quantum chemical descriptors · Corrosion inhibitors · Density functional theory (DFT) - Austenitic stainless steel · Quantitative structure and activity relationship (QSAR) · Molecular dynamics simulation

\section{Introduction}

Austenitic stainless steels are iron-chromium-nickel (Fe$\mathrm{Cr}-\mathrm{Ni}$ ) alloys. They may contain small amounts of other alloying elements, e.g., $\mathrm{Mn}, \mathrm{Nb}, \mathrm{Mo}, \mathrm{Si}, \mathrm{Al}$ and $\mathrm{Ti}$, which

Fahimeh Shojaie

f.shojaie@kgut.ac.ir

1 Department of Photonic, Institute of Science and High Technology and Environmental Sciences, Graduate University of Advanced Technology, Kerman, Iran

2 Imperial College Reactor Centre, Silwood Park, Ascot, Berkshire, UK may alter their specific properties. The formation of a passive layer of corrosion inhibitors on surfaces of these materials causes high corrosion resistance [1, 2]. Because of their strength, corrosion resistance, mechanical workability, and excellent electrical and thermal conductivities, austenitic stainless steels are one of the most important materials that are used widely in different industries [3-6]. The corrosion of stainless steel, especially when it occurs in acidic solution, is the concern of the steel users [7]. Acidic solutions are the cause of the detriment to many materials and considerable economic losses [8-10].

The corrosion inhibition efficiency depends on the structure, chemical composition, the nature of the metal and other conditions [11]. Theoretical studies of the efficiency of corrosion inhibitors have aimed at gaining insight on the molecular chemical activity, structural and electronic properties [12-17]. Newly, experimental and quantum chemical studies on inhibition of the corrosion of steel by two pyrazole compounds [18], benzothiazole derivatives [19], 1H-pyrrole-2,5-dione derivatives [20], some sulfonamides [21] and Schiff base molecules [22] have been calculated. The density functional theory calculations were performed on benzoin, benzil, benzoin-(4-phenylthiosemicarbazone) and benzil-(4-phenylthiosemicarbazone) used as corrosion inhibitors for mild steel in acidic medium by Kayadibi et al. [23]. The effect of temperature on corrosion and inhibition processes is discussed by Odozi et al. [24]. They showed that corrosion rate increases as temperature increases both in the absence and presence of the inhibitor and decreases further in the presence of the inhibitor. Radilla et al. [25] have studied the adsorption of the corrosion inhibitor 2-mercaptoimidazole onto Fe $\left(\begin{array}{lll}1 & 0 & 0\end{array}\right)$ surface.

The presence of heteroatoms with a number of lone pairs of electrons may result in the protonation of the inhibitor at 
the heteroatom centers. Therefore, several works have been done in this area. In the quinoline derivatives [26] (the $\mathrm{N}$ atom is the only heteroatom), protonated species is more electron deficient than the non-protonated species. Theoretical studies on phenazine and related compounds as corrosion inhibitors for mild steel in sulfuric acid medium [27] show that molecules with $\mathrm{N}$ atoms are preferentially protonated in acidic medium while molecules with $\mathrm{S}$ and $\mathrm{O}$ atoms do not prefer to undergo protonation, which confirms the results obtained from the calculation of the proton affinity. All the quinoxaline molecules have $\mathrm{N}$ atoms; they are all likely to be protonated in aqueous acid medium [28]. A comparison of the quantum chemical reactivity parameters for protonated species and the neutral species indicates the relative tendency of these species to interact with the metal surface.

The objective of this paper is to carry out a theoretical study on the corrosion inhibition effect of two pyrimidine derivatives, which have a class of sulfur and nitrogencontaining compounds. Caliskan et al. studied the corrosion inhibition effect of same pyrimidine derivatives in $1 \mathrm{M} \mathrm{HCl}$ solution at $298 \mathrm{~K}$ using polarization and impedance techniques [29]. The pyrimidine derivatives that were studied by us and also investigated by Caliskan et al. in their work are 5-Benzoyl-4-(4-carboxphenyl)-6phenyl-1,2,3,4-tetrahydro-2-iminopyrimidine (BCPTI) and 5-Benzoyl-4-tolyl-6-phenyl-1,2,3,4-tetrahydro-2-thioxopyrimidine (BTPTT) [29]. The composition of the studied austenitic chromium-nickel steel is as follows: (composition is expressed in weight \%) C: 0.0425 ; Si: 0.421; Mn: 2.13; P: 0.0133; S: 0.113; Cr: 18.51; Mo: 0.563; Ni: 8.34; Al: 0.0334; Co: 0.0901; Cu: 0.358; Fe: balance [29].

\section{Computational methods}

The calculations on BCPTI and BTPTT were performed by Gaussian09 [30] software using the B3LYP function and the $6-311++\mathrm{G}(\mathrm{d}, \mathrm{p})$ basis set. This software has been used specifically for systems containing transition metal atoms. These calculations were performed to investigate the structural parameters that affect the inhibition efficiency of the two pyrimidine derivatives and also to study the adsorption mechanisms on the austenitic stainless steel surface. From the optimized geometries of BCPTI and BTPTT, their global molecular descriptors [31-44] such as the energy of the highest occupied molecular orbital $\left(E_{\mathrm{HOMO}}\right)$, the energy of the lowest unoccupied molecular orbital $\left(E_{\mathrm{LUMO}}\right)$, the energy gap $(\Delta E)$, the ionization potential (IP), the electron affinity (EA), the global hardness $(\eta)$, the electronegativity $(\chi)$, the global softness $(\sigma)$, the electrophilicity $(\omega)$, the electrodonating $\left(\omega^{-}\right)$, the electroaccepting $\left(\omega^{+}\right)$, the net electrophilicity $\left(\Delta \omega^{ \pm}\right)$, the fraction of electron transferred $(\Delta N)$, the total negative charge (TNC) and the dipole moment $(\mu)$ were calculated. It is expected that the properties of molecules and ions to be different in gas and liquid phases. In this work, all calculations for solvent effect on the inhibitors were carried out using the IEFPCM method [45]. The theoretical results can be used to identify compounds with desired properties using quantitative structure activity relationship (QSAR) method [46]. The correlation between the inhibition efficiencies of the compounds indicated that QSAR method could be used to study the inhibitors. A quadratic model has been suggested to calculate the approximate inhibition efficiencies. According to this model, the regression analyses fitted the Caliskan et al. experimental data [29] well and the calculated inhibition efficiencies of the two pyrimidine derivatives were found to be close to their experimental values.

\section{Results and discussion}

\section{Reactivity parameters}

The structures and the optimized configurations of the BCPTI and PTPTT corrosion inhibitors are shown in Fig. 1. The inhibitor conformers are considered to be minima based on the absence of imaginary frequencies. The HOMO and the LUMO of the BCPTI and PTPTT inhibitors in gas and liquid phases are shown in Fig. 2.

The HOMO of the BCPTI molecule is delocalized throughout the system except on ring $\mathrm{d}$ and has maxima on $\mathrm{C} 2, \mathrm{C} 6, \mathrm{C} 4, \mathrm{C} 8$ and $\mathrm{C} 10$ atoms in particular on heteroatoms $\mathrm{N}$ and N2. The LUMO is delocalized throughout the BCPTI system except on ring a, and has maxima on ring $\mathrm{d}$ (see Fig. 2), $\mathrm{C} 12$ and $\mathrm{O}$ atoms in both gas and liquid phases. The HOMO of the BTPTT molecule is delocalized on ring $\mathrm{b}$ and has maxima on $\mathrm{S}$ and $\mathrm{C} 12$ atoms in gas phase. The maxima of the HOMO is delocalized on ring a, a slight delocalization on rings $b$ and $c$ and has maxima on $\mathrm{S}$ and $\mathrm{C} 12$ atoms. The LUMO is delocalized throughout the BTPTT system except on ring a in both phases (see Fig. 2). The LUMO of the BTPTT has maxima on $\mathrm{C} 12$ and $\mathrm{C} 10$ atoms in particular on heteroatoms $\mathrm{O}$ and $\mathrm{S}$ in both phases. The regions of a molecule on which their HOMO are distributed indicate the sites which have the highest tendency to interact with a metal surface. The LUMO indicates regions which have the highest tendency to accept electrons.

Table 1 shows the bond lengths and angles of the BCPTI and BTPTT inhibitors that are considered to be significant. A comparison of bond lengths and angles for both gas and liquid phases shows the effect of solvent on 
Fig. 1 The structures and the optimized geometries of the BCPTI and PTPTT inhibitors

$\begin{array}{lll}\text { Inhibitor Structure } & \text { Optimized geometries }\end{array}$

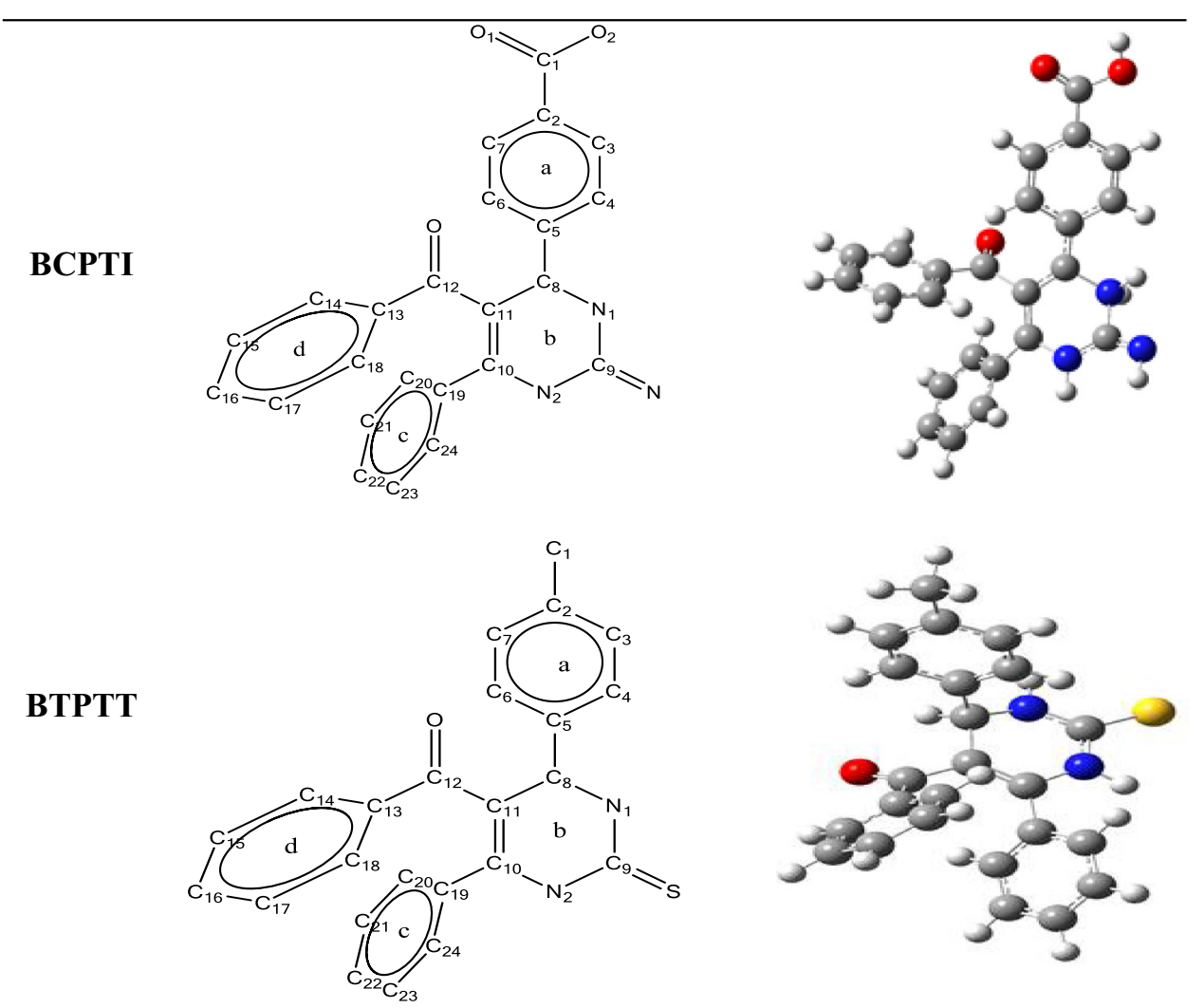

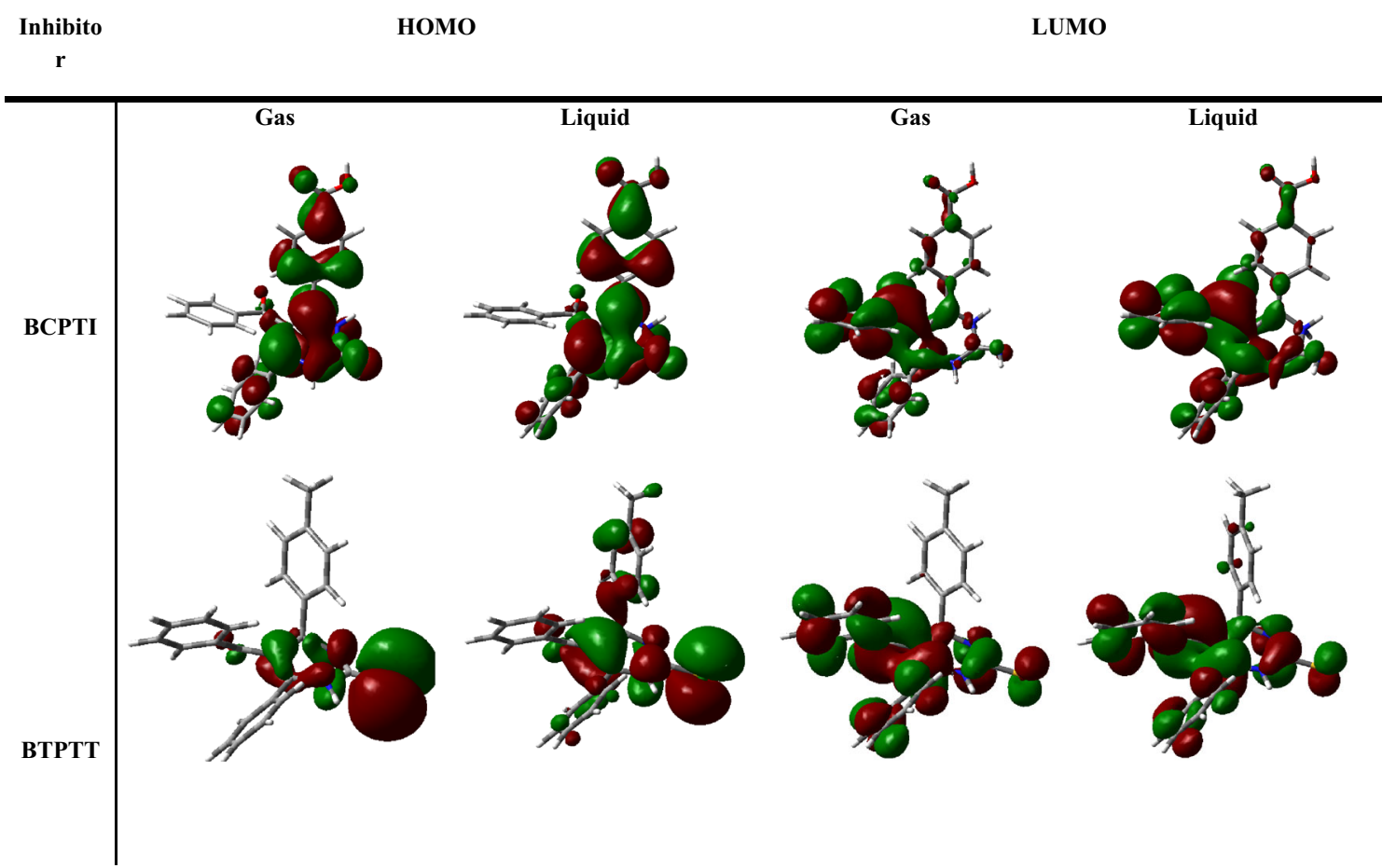

Fig. 2 The HOMO and the LUMO of the BCPTI and BTPTT inhibitors in gas and liquid 
Table 1 Comparison of the bond lengths and bond angles of BCPTI and BTPTT in gas and liquid phases

\begin{tabular}{|c|c|c|c|c|}
\hline & \multicolumn{2}{|l|}{ ВCPTI } & \multicolumn{2}{|l|}{ ВТРТT } \\
\hline & Gas & Solvent & Gas & Solvent \\
\hline \multicolumn{5}{|l|}{ Bond lengths $(\AA)$} \\
\hline $\mathrm{C} 1-\mathrm{O} 1$ & 1.214 & 1.225 & - & - \\
\hline $\mathrm{C} 1-\mathrm{O} 2$ & 1.367 & 1.364 & - & - \\
\hline $\mathrm{C} 1-\mathrm{C} 2$ & 1.469 & 1.457 & 1.509 & 1.509 \\
\hline $\mathrm{C} 2-\mathrm{C} 3$ & 1.400 & 1.408 & 1.400 & 1.403 \\
\hline $\mathrm{C} 3-\mathrm{C} 4$ & 1.385 & 1.380 & 1.392 & 1.391 \\
\hline C5-C6 & 1.422 & 1.431 & 1.397 & 1.395 \\
\hline $\mathrm{C} 2-\mathrm{C} 7$ & 1.407 & 1.412 & 1.394 & 1.396 \\
\hline $\mathrm{C} 5-\mathrm{C} 8$ & 1.430 & 1.416 & 1.529 & 1.527 \\
\hline C9-N1 & 1.490 & 1.487 & 1.347 & 1.337 \\
\hline $\mathrm{C} 9-\mathrm{S}$ & - & - & 1.675 & 1.695 \\
\hline $\mathrm{C} 9-\mathrm{N}$ & 1.274 & 1.271 & - & - \\
\hline $\mathrm{C} 9-\mathrm{N} 2$ & 1.349 & 1.354 & 1.377 & 1.368 \\
\hline $\mathrm{C} 10-\mathrm{C} 11$ & 1.379 & 1.376 & 1.353 & 1.353 \\
\hline $\mathrm{C} 12-\mathrm{O}$ & 1.217 & 1.225 & 1.225 & 1.229 \\
\hline $\mathrm{C} 10-\mathrm{N} 2$ & 1.428 & 1.418 & 1.400 & 1.402 \\
\hline \multicolumn{5}{|l|}{ Bond angles $\left({ }^{\circ}\right)$} \\
\hline $\mathrm{O} 1-\mathrm{C} 1-\mathrm{O} 2$ & 121.016 & 120.390 & - & - \\
\hline $\mathrm{C} 1-\mathrm{C} 2-\mathrm{C} 3$ & 120.827 & 122.922 & 120.976 & 120.788 \\
\hline $\mathrm{C} 4-\mathrm{C} 5-\mathrm{C} 6$ & 116.099 & 115.512 & 118.476 & 118.499 \\
\hline $\mathrm{C} 1-\mathrm{C} 2-\mathrm{C} 7$ & 119.047 & 119.611 & 121.164 & 121.294 \\
\hline $\mathrm{C} 8-\mathrm{N} 1-\mathrm{C} 9$ & 111.948 & 110.761 & 126.219 & 126.219 \\
\hline $\mathrm{N}-\mathrm{C} 9-\mathrm{N} 2-\mathrm{C} 10$ & 134.433 & 133.305 & - & - \\
\hline $\mathrm{S}-\mathrm{C} 9-\mathrm{N} 2$ & - & - & 121.120 & 120.866 \\
\hline $\mathrm{C} 11-\mathrm{C} 12-\mathrm{O}$ & 119.149 & 119.773 & 118.774 & 118.729 \\
\hline $\mathrm{N} 2-\mathrm{C} 10-\mathrm{C} 11$ & 116.497 & 117.226 & 119.632 & 119.416 \\
\hline $\mathrm{C} 11-\mathrm{C} 12-\mathrm{C} 13$ & 119.551 & 119.708 & 121.348 & 121.434 \\
\hline $\mathrm{C} 13-\mathrm{C} 14-\mathrm{C} 15$ & 120.353 & 120.435 & 120.359 & 120.372 \\
\hline $\mathrm{C} 15-\mathrm{C} 16-\mathrm{C} 17$ & 120.031 & 120.004 & 119.965 & 119.986 \\
\hline C13-C18-C17 & 120.301 & 120.315 & 120.271 & 120.249 \\
\hline $\mathrm{C} 19-\mathrm{C} 20-\mathrm{C} 21$ & 120.959 & 120.826 & 120.368 & 120.257 \\
\hline C22-C23-C24 & 120.345 & 120.342 & 120.130 & 120.157 \\
\hline $\mathrm{C} 8-\mathrm{C} 11-\mathrm{C} 12-\mathrm{O}$ & 60.341 & 49.667 & 39.617 & 39.617 \\
\hline $\mathrm{C} 1-\mathrm{C} 2-\mathrm{C} 3-\mathrm{C} 4$ & -179.952 & -179.875 & -178.524 & -178.898 \\
\hline C7-C6-C5-C8 & 179.475 & -179.644 & 178.384 & 179.853 \\
\hline $\mathrm{C} 5-\mathrm{C} 8-\mathrm{N} 1-\mathrm{C} 9$ & 133.249 & 125.255 & 101.833 & 103.701 \\
\hline $\mathrm{N}-\mathrm{C} 9-\mathrm{N} 2-\mathrm{C} 10$ & 169.358 & 166.365 & - & - \\
\hline $\mathrm{S}-\mathrm{C} 9-\mathrm{N} 2-\mathrm{C} 10$ & - & - & -171.249 & -170.308 \\
\hline C10-C19-C20-C21 & -179.575 & -179.987 & 177.907 & 177.973 \\
\hline N2-C10-C19-C24 & 39.085 & 44.561 & 52.437 & 54.477 \\
\hline C12-C13-C14-C15 & -178.151 & -177.517 & -176.595 & -176.379 \\
\hline $\mathrm{C} 12-\mathrm{C} 13-\mathrm{C} 18-\mathrm{C} 17$ & 177.624 & 176.693 & 175.380 & 175.127 \\
\hline
\end{tabular}

the geometry. The changes in the bond lengths are less than 0.014 and $0.02 \AA$ for BCPTI and BTPTT, respectively. This suggests that protonation has minimal influence on the bond lengths of the inhibitors. The bond angles vary (in both directions) by $<3^{\circ}$ in both structures with the exception of the C8-C11-C12-O, C5-C8-N1-C9 and N2-C10$\mathrm{C} 19-\mathrm{C} 24$ in BCPTI structure. The lengthening of $\mathrm{C} 1=\mathrm{O} 1$ (1.225 $\AA$ ) and C9-S (1.695 $\mathrm{A})$ bond distances in their 
Table 2 The quantum chemical descriptors of the BCPTI and BTPTT

\begin{tabular}{|c|c|c|c|c|c|c|c|}
\hline \multirow[t]{2}{*}{ Molecular descriptors } & \multirow[t]{2}{*}{ Parameter } & \multicolumn{2}{|l|}{$\mathrm{BCPTI}=\mathrm{BC}$} & \multicolumn{2}{|l|}{$\mathrm{BTPTT}=\mathrm{BT}$} & \multicolumn{2}{|c|}{ Comments } \\
\hline & & Gas & Liquid & Gas & Liquid & Gas & Liquid \\
\hline $\mathrm{HOMO}(\mathrm{eV})$ & - & -4.631 & -6.683 & -5.979 & -6.384 & $\mathrm{BC}>\mathrm{BT}$ & $\mathrm{BT}>\mathrm{BC}$ \\
\hline LUMO(eV) & - & -2.192 & -2.332 & -2.283 & -2.415 & $\mathrm{BC}>\mathrm{BT}$ & $\mathrm{BC}>\mathrm{BT}$ \\
\hline$\Delta \mathrm{E}(\mathrm{eV})$ & - & 2.439 & 4.351 & 3.696 & 3.969 & $\mathrm{BT}>\mathrm{BC}$ & $\mathrm{BC}>\mathrm{BT}$ \\
\hline \multicolumn{8}{|l|}{ Ionization Potential(IP) } \\
\hline $\mathrm{IP}=[\mathrm{E}(+1)-\mathrm{E}(0)]^{\mathrm{a}}$ & Energetic & 5.865 & 6.772 & 7.533 & 5.615 & $\mathrm{BT}>\mathrm{BC}$ & $\mathrm{BC}>\mathrm{BT}$ \\
\hline $\mathrm{IP}=-\mathrm{E}_{\mathrm{HOMO}}^{\mathrm{b}}$ & Orbital & 4.631 & 6.683 & 5.979 & 6.384 & $\mathrm{BT}>\mathrm{BC}$ & $\mathrm{BC}>\mathrm{BT}$ \\
\hline \multicolumn{8}{|l|}{ Electron Affinity(EA)(eV) } \\
\hline $\mathrm{EA}=[\mathrm{E}(0)-\mathrm{E}(-1)]^{\mathrm{c}}$ & Energetic & 0.909 & 2.489 & 0.972 & 0.453 & $\mathrm{BT}>\mathrm{BC}$ & $\mathrm{BT}>\mathrm{BC} \quad \mathrm{BT}>\mathrm{BC}$ \\
\hline $\mathrm{EA}=-\mathrm{E}_{\mathrm{LUMO}}^{\mathrm{a}}$ & Orbital & 2.192 & 2.332 & 2.283 & 2.415 & $\mathrm{BT}>\mathrm{BC}$ & \\
\hline Global hardness $(\eta)(e V)$ & Energetic & 2.479 & 2.141 & 3.28 & 2.581 & $\mathrm{BT}>\mathrm{BC}$ & $\mathrm{BT}>\mathrm{BC} \mathrm{BC}>\mathrm{BT}$ \\
\hline$\eta=(\mathrm{I}-\mathrm{A}) / 2^{\mathrm{d}}$ & Orbital & 1.219 & 2.175 & 1.848 & 1.984 & $\mathrm{BT}>\mathrm{BC}$ & \\
\hline Chemical potential $(\chi)(\mathrm{eV})$ & Energetic & 3.386 & 4.63 & 4.252 & 3.034 & $\mathrm{BT}>\mathrm{BC}$ & $\mathrm{BC}>\mathrm{BT} \mathrm{BC}>\mathrm{BT}$ \\
\hline$\chi(\mathrm{I}+\mathrm{A}) / 2^{\mathrm{d}}$ & Orbital & 3.411 & 4.507 & 4.131 & 4.399 & $\mathrm{BT}>\mathrm{BC}$ & \\
\hline Global softness $(\sigma)(\mathrm{eV})$ & Energetic & 0.403 & 0.467 & 0.305 & 0.387 & $\mathrm{BC}>\mathrm{BT}$ & $\mathrm{BC}>\mathrm{BT} \quad \mathrm{BT}>\mathrm{BC}$ \\
\hline$\sigma=1 / /^{\eta \mathrm{e}}$ & Orbital & 0.82 & 0.459 & 0.541 & 0.504 & $\mathrm{BC}>\mathrm{BT}$ & \\
\hline Electrophilicity $(\omega)(\mathrm{eV})$ & Energetic & 2.312 & 5.006 & 2.756 & 1.783 & $\mathrm{BT}>\mathrm{BC}$ & $\mathrm{BC}>\mathrm{BT} \quad \mathrm{BT}>\mathrm{BC}$ \\
\hline$\omega=\chi^{2} / 2 \eta^{\mathrm{f}}$ & Orbital & 4.772 & 4.669 & 4.617 & 4.877 & $\mathrm{BC}>\mathrm{BT}$ & \\
\hline Electrodonating $\left(\omega^{-}\right)(\mathrm{eV})$ & Energetic & 4.315 & 7.589 & 5.292 & 3.623 & $\mathrm{BT}>\mathrm{BC}$ & $\mathrm{BC}>\mathrm{BT}$ \\
\hline$\omega^{-}=(3 \mathrm{I}+\mathrm{A})^{2} / 16(\mathrm{I}-\mathrm{A})^{\mathrm{g}}$ & Orbital & 6.629 & 7.195 & 6.914 & 7.324 & $\mathrm{BT}>\mathrm{BC}$ & $\mathrm{BT}>\mathrm{BC}$ \\
\hline Electroaccepting $\left(\omega^{+}\right)(\mathrm{eV})$ & Energetic & 0.929 & 2.958 & 1.04 & 0.589 & $\mathrm{BT}>\mathrm{BC}$ & $\mathrm{BC}>\mathrm{BT}$ \\
\hline$\omega^{+}=(\mathrm{I}+3 \mathrm{~A})^{2} / 16(\mathrm{I}-\mathrm{A})^{\mathrm{g}}$ & Orbital & 3.218 & 2.688 & 2.783 & 2.925 & $\mathrm{BC}>\mathrm{BT}$ & $\mathrm{BT}>\mathrm{BC}$ \\
\hline net electrophilicity $\left(\Delta \omega^{ \pm}\right)(\mathrm{eV})$ & Energetic & 5.244 & 10.547 & 6.333 & 4.212 & $\mathrm{BT}>\mathrm{BC}$ & $\mathrm{BC}>\mathrm{BT}$ \\
\hline$\Delta \omega^{ \pm}=\left(\omega^{+}+\omega^{-}\right)^{\mathrm{h}}$ & Orbital & 9.847 & 9.883 & 9.697 & 10.249 & $\mathrm{BC}>\mathrm{BT}$ & $\mathrm{BT}>\mathrm{BC}$ \\
\hline back-donation $\left(\Delta \mathrm{E}_{\mathrm{T}}\right)(\mathrm{eV})$ & Energetic & -0.619 & -0.535 & -0.82 & -0.645 & $\mathrm{BC}>\mathrm{BT}$ & $\mathrm{BC}>\mathrm{BT}$ \\
\hline$\Delta \mathrm{E}_{\mathrm{T}}=-\eta / 4^{\mathrm{i}}$ & Orbital & -0.305 & -0.544 & -0.462 & -0.496 & $\mathrm{BC}>\mathrm{BT}$ & $\mathrm{BT}>\mathrm{BC}$ \\
\hline Transferred electrons $(\Delta \mathrm{N})$ & Energetic & 0.729 & 0.553 & 0.419 & 0.768 & $\mathrm{BC}>\mathrm{BT}$ & $\mathrm{BT}>\mathrm{BC}$ \\
\hline$\Delta \mathrm{N}=\left(\chi_{\mathrm{Fe}}-\chi_{\mathrm{inh}}\right) / 2\left(\eta_{\mathrm{Fe}}+\eta_{\mathrm{inh}}\right)^{\mathrm{m}}$ & Orbital & 1.471 & 0.573 & 0.776 & 0.655 & $\mathrm{BC}>\mathrm{BT}$ & $\mathrm{BT}>\mathrm{BC}$ \\
\hline Total Negative Charge(TNC) & - & 7.658 & 8.139 & 8.344 & 8.077 & $\mathrm{BT}>\mathrm{BC}$ & $\mathrm{BC}>\mathrm{BT}$ \\
\hline Dipole moment $(\mu)(D)$ & - & 7.827 & 14.565 & 5.807 & 7.954 & $\mathrm{BC}>\mathrm{BT}$ & $\mathrm{BC}>\mathrm{BT}$ \\
\hline ET (a.u) & - & -1316.222 & -1316.265 & -1509.846 & -1509.865 & $\mathrm{BC}>\mathrm{BT}$ & $\mathrm{BC}>\mathrm{BT}$ \\
\hline
\end{tabular}

${ }^{\mathrm{a}}$ Ref. [48], ${ }^{\mathrm{b}}$ Ref. [49], ${ }^{\mathrm{c}}$ Ref. [50], ${ }^{\mathrm{d}}$ Ref. [51], ${ }^{\mathrm{e}}$ Ref. [52], ${ }^{\mathrm{f}}$ Ref. [53], ${ }^{\mathrm{g}}$ Ref. [40], ${ }^{\mathrm{h}}$ Ref. [41], ${ }^{\mathrm{i}}$ Ref. [42], ${ }^{\mathrm{m}}$ Ref. [27]

respective structures was noted in liquid phase which is probably the result of the high polarity of these bonds.

The quantum chemical descriptors are listed in Table 2 for the BCPTI and BTPTT molecules in gas and liquid phases. Table 2 descriptors were calculated by both energetic parameter and orbital parameter methods. The quantum chemical descriptors of the BCPTI and BTPTT molecules are not similar in gas and liquid phases in particular the dipole moment of BCPTI compound.

The binding ability of the BCPTI and BTPTT inhibitors to a metal surface increases with increasing HOMO and decreasing LUMO energies. The higher the value of $E_{\mathrm{HOMO}}$ becomes, the lower will be the capability of an inhibitor to accept electrons because the $E_{\mathrm{HOMO}}$ describes the electron-donating ability of the inhibitor. The energy of the LUMO indicates the ability of a molecule to accept electrons and thus the lower the value of $E_{\mathrm{LUMO}}$ becomes, the more probable that the molecule would accept electrons. Table 2 shows BCPTI and BTPTT have similar $E_{\mathrm{HOMO}}$ in gas and liquid phases but the $E_{\mathrm{LUMO}}$ of BTPTT is lower than the $E_{\mathrm{LUMO}}$ of BCPTI in both phases.

The gap between the HOMO and LUMO energy levels of the BCPTI and BTPTT molecules is a function of reactivity of the inhibitors with a metallic surface. The BCPTI and BTPTT have similar energy gaps in gas phase but BTPTT has a lower energy gap in liquid phase. The 

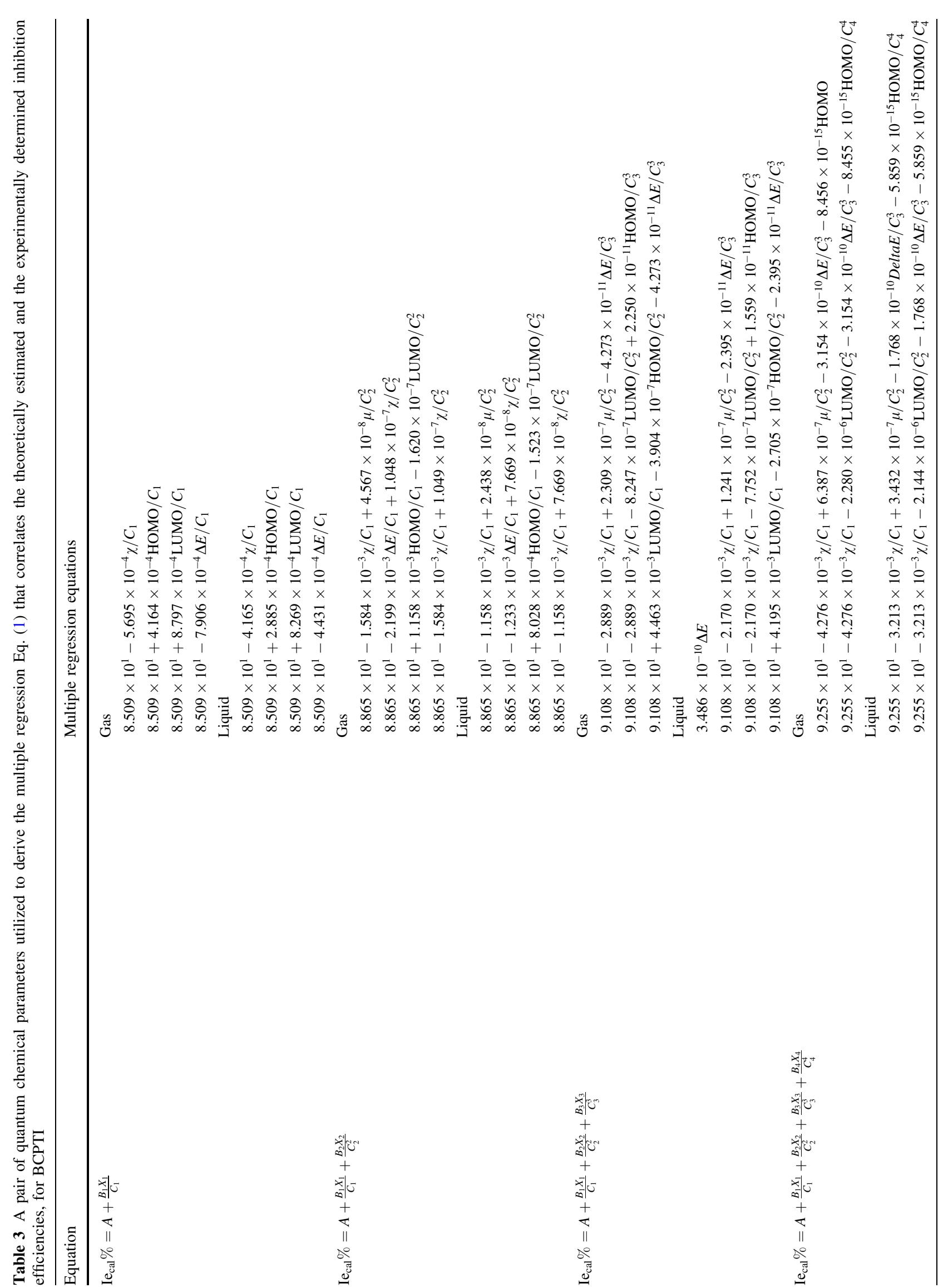
Table 4 A pair of quantum chemical parameters utilized to derive the multiple regression Eq. (1) that correlates the theoretically estimated and the experimentally determined inhibition efficiencies, for BTPTT

\begin{tabular}{|c|c|}
\hline Equation & Multiple regression equations \\
\hline $\mathrm{Ie}_{\mathrm{cal}} \%=A+\frac{B_{1} X_{1}}{C_{1}}$ & $\begin{array}{l}\text { Gas } \\
\begin{array}{l}9.061 \times 10^{1}-3.388 \times 10^{-4} \chi / C_{1} \\
9.061 \times 10^{1}+2.398 \times 10^{-4} \mathrm{HOMO} / C_{1} \\
9.061 \times 10^{1}+6.281 \times 10^{-4} \mathrm{LUMO} / C_{1} \\
9.061 \times 10^{1}-3.879 \times 10^{-4} \Delta E / C_{1} \\
\text { Liquid } \\
9.061 \times 10^{1}-4.726 \times 10^{-4} \chi / C_{1} \\
9.061 \times 10^{1}+2.246 \times 10^{-4} \mathrm{HOMO} / C_{1} \\
9.061 \times 10^{1}+5.937 \times 10^{-4} \mathrm{LUMO} / C_{1} \\
9.061 \times 10^{1}-3.613 \times 10^{-4} \Delta E / C_{1}\end{array}\end{array}$ \\
\hline $\mathrm{Ie}_{\mathrm{cal}} \%=A+\frac{B_{1} X_{1}}{C_{1}}+\frac{B_{2} X_{2}}{C_{2}^{2}}$ & $\begin{array}{l}\text { Gas } \\
9.326 \times 10^{1}-9.383 \times 10^{-4} \chi / C_{1}+4.547 \times 10^{-8} \mu / C_{2}^{2} \\
9.326 \times 10^{1}-1.079 \times 10^{-3} \Delta E / C_{1}+6.209 \times 10^{-8} \chi / C_{2}^{2} \\
9.326 \times 10^{1}+6.672 \times 10^{-4} \mathrm{HOMO} / C_{1}-1.156 \times 10^{-7} \mathrm{LUMO} / C_{2}^{2} \\
9.326 \times 10^{1}-9.383 \times 10^{-4} \chi / C_{1}+6.209 \times 10^{-8} \chi / C_{2}^{2} \\
\text { Liquid } \\
9.326 \times 10^{1}-1.315 \times 10^{-3} \chi / C_{1}+3.319 \times 10^{-8} \mu / C_{2}^{2} \\
9.326 \times 10^{1}-1.005 \times 10^{-3} \Delta E / C_{1}+8.730 \times 10^{-8} \chi / C_{2}^{2} \\
9.326 \times 10^{1}+6.249 \times 10^{-4} \mathrm{HOMO} / C_{1}-1.093 \times 10^{-7} \mathrm{LUMO} / C_{2}^{2} \\
9.326 \times 10^{1}-1.315 \times 10^{-3} \chi / C_{1}+8.703 \times 10^{-8} \chi / C_{2}^{2}\end{array}$ \\
\hline $\mathrm{Ie}_{\mathrm{cal}} \%=A+\frac{B_{1} X_{1}}{C_{1}}+\frac{B_{2} X_{2}}{C_{2}^{2}}+\frac{B_{3} X_{3}}{C_{3}^{3}}$ & $\begin{array}{l}\text { Gas } \\
9.507 \times 10^{1}-1.711 \times 10^{-3} \chi / C_{1}+2.315 \times 10^{-7} \mu / C_{2}^{2}-2.096 \times 10^{-11} \Delta E / C_{3}^{3} \\
9.507 \times 10^{1}-1.711 \times 10^{-3} \chi / C_{1}-5.888 \times 10^{-7} \mathrm{LUMO} / C_{2}^{2}+1.296 \times 10^{-11} \mathrm{HOMO} / C_{3}^{3} \\
9.507 \times 10^{1}+3.186 \times 10^{-3} \mathrm{LUMO}_{i}-2.248 \times 10^{-7} \mathrm{HOMO} / C_{2}^{2}-2.096 \times 10^{-11} \Delta E / C_{3}^{3} \\
\text { Liquid } \\
9.507 \times 10^{1}-2.398 \times 10^{-3} \chi / C_{1}+1.690 \times 10^{-7} \mu / C_{2}^{2}-1.952 \times 10^{-11} \Delta E / C_{3}^{3} \\
9.507 \times 10^{1}-2.398 \times 10^{-3} \chi / C_{1}-5.566 \times 10^{-7} \mathrm{LUMO} / C_{2}^{2}+1.214 \times 10^{-11} \mathrm{HOMO} / C_{3}^{3} \\
9.507 \times 10^{1}+3.012 \times 10^{-3} \mathrm{LUMO} C_{i}-2.105 \times 10^{-7} \mathrm{HOMO} / C_{2}^{2}-1.952 \times 10^{-11} \Delta E / C_{3}^{3}\end{array}$ \\
\hline
\end{tabular}

binding ability of the inhibitors to a metal surface increases with decreasing energy gap. This means that the BTPTT molecule could perform better as a corrosion inhibitor in liquid phase.

Ionization potential (IP) is a basic descriptor of the chemical reactivity of atoms and molecules. IP is the minimum energy required to remove an electron from an atom. Chemical potential indicates the molecular capability of accepting electrons. A low IP indicates less energy needed to remove electrons from a system and also low stability. Similarly, a low chemical potential indicates low stability. Table 2 shows BCPTI and BTPTT have low ionization energies in gas and liquid phases.

The absolute hardness and softness are important properties for measuring a molecular stability and reactivity. Table 2 shows that BCPTI has a lower hardness and a higher softness in gas and liquid phases (except for values obtained by orbital parameter method) which reflect the high reactivity of BCPTI as compared with BTPTT.

A hard molecule has a large energy gap and a soft molecule has a small energy gap. Soft molecules are more reactive than hard ones because they could easily offer electrons to an electron acceptor. BCPTI is a soft molecule in both gas and liquid phases. It has a small energy gap in gas phase but a large energy gap in liquid phase. BCPTI molecule is more reactive than BTPTT in gas phase but is less reactive than BTPTT in liquid phase as indicated by calculations based on orbital parameter. The ability of an inhibitor molecule to accept electrons is described by its electrophilicity index. Electrophilicity is a measure of the energy stabilization after a system accepts additional amount of electron charge from its environment.

Based on energetic parameter calculations, BCPTI has a lower value of electrophilicity in gas phase and therefore 


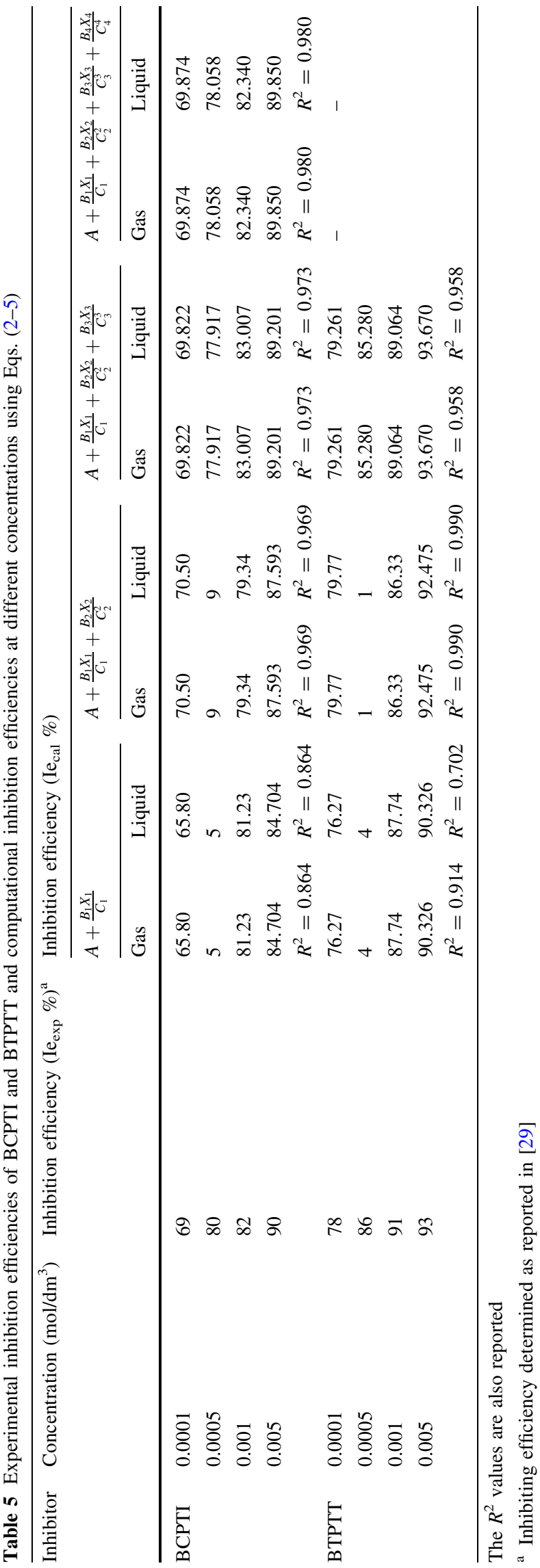

this molecule is a stronger nucleophile than BTPTT but based on orbital parameter calculations, the BCPTI is a weaker nucleophile than BTPTT in liquid phase. A larger electroaccepting value corresponds to a better capability of accepting charge, whereas a smaller value of electrodonating value of a system makes it a better electron donor [47].

The calculated electrodonating, electroaccepting and net electrophilicity values of the BCPTI and BTPTT inhibitors are listed in Table 2. The energy parameter indicates BCPTI is a better electron donor than BTPTT in gas phase and the orbital parameter indicates BCPTI is also a better electron donor than BTPTT in liquid phase. In contrast to this, the energy parameter indicates BTPTT molecule has a better capability of accepting charge in gas phase and the orbital parameter indicates BTPTT molecule has also a better capability of accepting charge in liquid phase. The total electrophilicity indicates BCPTI is the strongest nucleophile in gas phase if energy parameter is applied and also is the strongest nucleophile in liquid phase if orbital parameter is applied. In contrast to this, BTPTT molecule is the strongest nucleophile in gas phase if orbital parameter is applied and also is the strongest nucleophile in liquid phase if energy parameter is applied. These are similar to the results obtained by the electrophilicity index. The calculated back-donation $\left(\Delta E_{\mathrm{T}}\right)$ values of the inhibitors are listed in Table 2. This Table shows the back-donation $\left(\Delta E_{\mathrm{T}}\right)$ values are similar to global softness values $(\sigma)$.

The trend of electrons' donation within a set of inhibitors is described by the fraction of electrons transferred $(\Delta N)$. If $\Delta N$ is below $3.6 \mathrm{eV}$, then the inhibition efficiency increases with increasing $\omega^{-}$ability at the mild steel interface [48]. Table 2 shows that all values of the $\Delta N$ are below $3.6 \mathrm{eV}$ and the BCPTI and BTPTT have the highest values of $\Delta N$ in gas and liquid phases. Because iron is the major constituent of austenitic stainless steel, the theoretical values of the iron electronegativity $\left(\chi_{\mathrm{Fe}}=7 \mathrm{eV}\right)$ and the iron global hardness $\left(\eta_{\mathrm{Fe}}=0\right)$ were used to compute $\Delta N$ for the various Hamiltonians [49].

The calculations show that BTPTT and BCPTI have the highest TNC values in gas and liquid phases. The adsorption of the inhibitor onto the mild steel surface is enhanced at higher TNC values. The TNC values of the BTPTT and BCPTI molecules are higher in liquid phase than in gas phase.

Information about the polarity of a molecule describes its $\mu$. In general, there is no significant relationship between the $\mu$ values and inhibition efficiencies. In some systems, the $\mu$ appears to increase with increasing inhibition efficiencies [50] while in some other systems the $\mu$ appears to decrease as the inhibition efficiency increases [51]. Table 2 shows that BCPTI has the highest $\mu$ value in gas and liquid phases and the highest molecular mass. There is a 

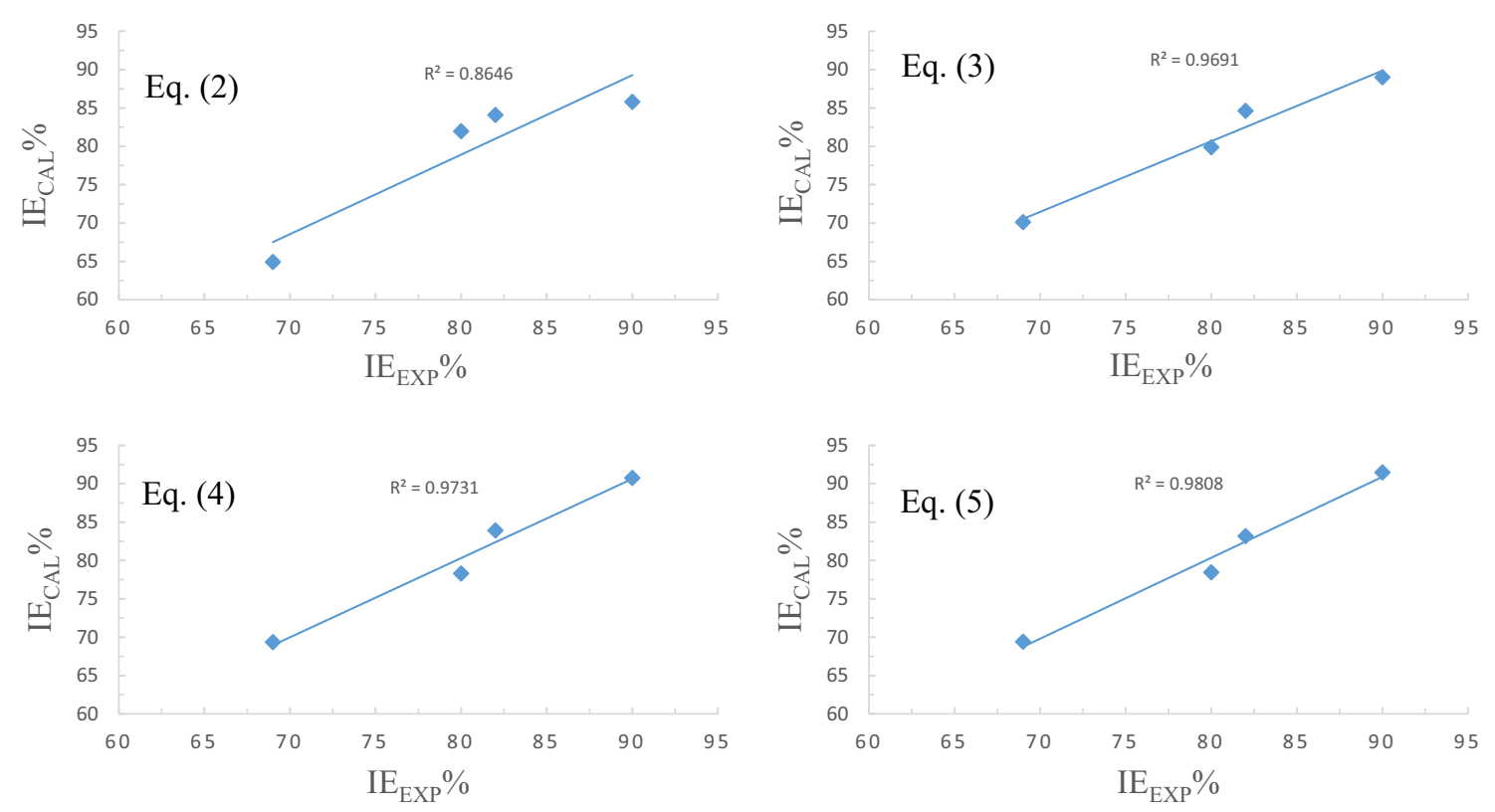

Fig. 3 The plots of experimental inhibition efficiencies of BCPTI and computational inhibition efficiencies at different concentrations using Eqs. (2-5). The R2 values are also reported
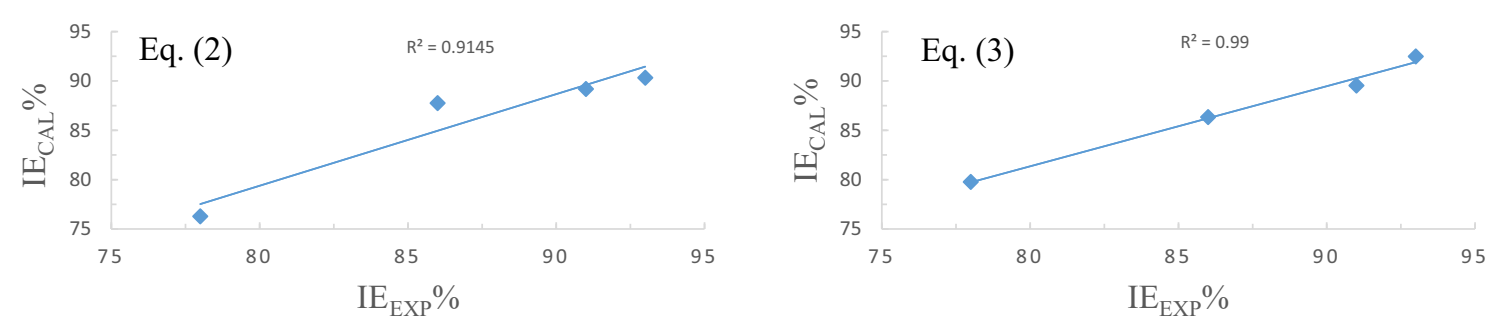

Fig. 4 The plots of experimental inhibition efficiencies of BTPTT and computational inhibition efficiencies at different concentrations using Eqs. $(2,3)$. The $\mathrm{R} 2$ values are also reported

correlation between the molecular mass and the inhibition efficiency. As a molecular mass increases, its adsorption on a metal surface will increase. Inhibition efficiency increases as adsorption increases. It is clear from Table 2 that $\mu$ is higher in water than in gas and this is an indication of the polarization effect of the solvent on the inhibitor molecules. The difference between the $\mu$ values of BTPTT in gas and water is 2.02 but for BCPTI this difference is 6.61 . This demonstrates that the polarization effect of the solvent on BCPTI molecule is more than its effect on the BTPTT molecule. This is because BCPTI has two oxygen atoms and a nitrogen atom but BTPTT has a sulfur atom.

From the computed results obtained for gas and liquid phases (Table 2), we can easily notice the stabilization effect of the solvent on the significant decrease of the $E_{\mathrm{T}}$ values of the two inhibitors. The $E_{\mathrm{T}}$ values show that BCPTI is more stable than BTPTT.

\section{QSAR consideration}

The QSAR method was used to correlate the inhibition efficiencies of the BCPTI and BTPTT with their molecular structures in gas and liquid phases. Attempts were made to establish a relationship between the experimental corrosion inhibition efficiencies and the calculated quantum chemical parameters. To obtain equations that are useful in predicting inhibition efficiency $\left(\mathrm{Ie}_{\mathrm{cal}}\right)$ from the concentrations of the inhibitors and their quantum chemical parameters, Eq. (1) has been proposed to calculate the $\mathrm{Ie}_{\mathrm{cal}}$.

$\mathrm{Ie}_{\text {calc }} \%=A+\frac{B_{1} X_{1}}{C_{1}}+\frac{B_{2} X_{2}}{C_{2}^{2}}+\frac{B_{3} X_{3}}{C_{3}^{3}}+\cdots \in+\frac{B_{n} X_{n}}{C_{n}^{n}}$,

where $A$ and $B_{n}$ are constants obtained by regression analysis, $X_{n}$ parameters are the independent variables consisting of quantum chemical values and $C_{n}$ parameters are the 
Table 6 Calculated Mulliken atomic charges for BCPTI using DFT at the B3LYP/++6-31G $(\mathrm{d}, \mathrm{p})$ basis set

\begin{tabular}{|c|c|c|c|c|c|c|}
\hline \multirow[t]{2}{*}{ Atom } & \multicolumn{2}{|l|}{ QN } & \multicolumn{2}{|l|}{$\mathrm{QN}+1$} & \multicolumn{2}{|l|}{$\mathrm{QN}-1$} \\
\hline & Gas & Liquid & Gas & Liquid & Gas & Liquid \\
\hline $\mathrm{C} 1$ & 0.294 & 0.305 & 0.304 & 0.301 & 0.286 & 0.309 \\
\hline $\mathrm{C} 2$ & 0.701 & 0.673 & 0.666 & 0.635 & 0.795 & 0.799 \\
\hline $\mathrm{C} 3$ & -0.692 & -0.649 & -0.722 & -0.656 & -0.716 & -0.676 \\
\hline $\mathrm{C} 4$ & -0.163 & -0.224 & -0.224 & -0.266 & -0.139 & -0.159 \\
\hline $\mathrm{C} 5$ & 0.996 & 0.927 & 1.004 & 0.949 & 0.952 & 0.954 \\
\hline C6 & -0.998 & -1.081 & -0.991 & -1.076 & -0.939 & -1.052 \\
\hline $\mathrm{C} 7$ & -0.548 & -0.596 & -0.554 & -0.640 & -0.510 & -0.568 \\
\hline $\mathrm{C} 8$ & -0.293 & -0.466 & -0.258 & -0.428 & -0.240 & -0.367 \\
\hline C9 & -0.050 & 0.005 & -0.036 & 0.017 & -0.112 & -0.064 \\
\hline $\mathrm{C} 10$ & -0.983 & -0.217 & -1.040 & -0.253 & -0.844 & -0.223 \\
\hline $\mathrm{C} 11$ & 0.741 & 0.205 & 0.777 & 0.242 & 0.629 & 0.237 \\
\hline $\mathrm{C} 12$ & -0.897 & -0.672 & -0.953 & -0.676 & -0.816 & -0.693 \\
\hline $\mathrm{C} 13$ & 0.630 & 0.497 & 0.752 & 0.532 & 0.588 & 0.482 \\
\hline $\mathrm{C} 14$ & 0.428 & 0.220 & 0.332 & 0.133 & 0.382 & 0.208 \\
\hline $\mathrm{C} 15$ & -0.425 & -0.507 & -0.425 & -0.508 & -0.423 & -0.503 \\
\hline $\mathrm{C} 16$ & -0.387 & -0.386 & -0.420 & -0.435 & -0.384 & -0.379 \\
\hline $\mathrm{C} 17$ & -0.099 & -0.088 & -0.133 & -0.147 & -0.077 & -0.063 \\
\hline $\mathrm{C} 18$ & -0.504 & -0.298 & -0.534 & -0.378 & -0.492 & -0.308 \\
\hline $\mathrm{C} 19$ & 0.959 & 0.657 & 0.947 & 0.648 & 0.938 & 0.719 \\
\hline $\mathrm{C} 20$ & -0.770 & -0.529 & -0.701 & -0.471 & -0.744 & -0.567 \\
\hline $\mathrm{C} 21$ & -0.361 & -0.410 & -0.374 & -0.426 & -0.334 & -0.391 \\
\hline $\mathrm{C} 22$ & -0.324 & -0.357 & -0.341 & -0.376 & -0.294 & -0.335 \\
\hline $\mathrm{C} 23$ & -0.267 & -0.285 & -0.276 & -0.299 & -0.253 & -0.273 \\
\hline $\mathrm{C} 24$ & -0.065 & -0.088 & -0.137 & -0.163 & -0.024 & -0.056 \\
\hline N1 & 0.205 & 0.221 & 0.202 & 0.205 & 0.198 & 0.258 \\
\hline $\mathrm{N}$ & -0.291 & -0.373 & -0.351 & -0.420 & -0.196 & -0.274 \\
\hline $\mathrm{N} 2$ & -0.063 & -0.061 & -0.066 & -0.081 & -0.045 & -0.021 \\
\hline $\mathrm{O} 1$ & -0.314 & -0.410 & -0.359 & -0.433 & -0.255 & -0.350 \\
\hline $\mathrm{O} 2$ & -0.200 & -0.232 & -0.215 & -0.242 & -0.183 & -0.208 \\
\hline $\mathrm{O}$ & -0.119 & -0.210 & -0.235 & -0.398 & -0.104 & -0.181 \\
\hline
\end{tabular}

inhibitor concentrations. The Eq. (1) shows that inhibition efficiency strongly depends on density parameter. To simplify the Eq. (1), only the first four terms were used.

$$
\begin{aligned}
& \mathrm{Ie}_{\text {calc }}=A+\frac{B_{1} X_{1}}{C_{1}} \\
& \mathrm{Ie}_{\text {calc }} \%=A+\frac{B_{1} X_{1}}{C_{1}}+\frac{B_{2} X_{2}}{C_{2}^{2}} \\
& \mathrm{Ie}_{\text {calc }} \%=A+\frac{B_{1} X_{1}}{C_{1}}+\frac{B_{2} X_{2}}{C_{2}^{2}}+\frac{B_{3} X_{3}}{C_{3}^{3}} \\
& \mathrm{Ie}_{\text {calc }} \%=A+\frac{B_{1} X_{1}}{C_{1}}+\frac{B_{2} X_{2}}{C_{2}^{2}}+\frac{B_{3} X_{3}}{C_{3}^{3}}+\frac{B_{4} X_{4}}{C_{4}^{4}} .
\end{aligned}
$$

Equations (2-5) were utilized to correlate the composite

\begin{tabular}{|c|c|c|c|c|c|c|}
\hline \multirow[t]{2}{*}{ Atom } & \multicolumn{2}{|l|}{$\mathrm{Q}_{\mathrm{N}}$} & \multicolumn{2}{|c|}{$\mathrm{QN}+1$} & \multicolumn{2}{|l|}{$\mathrm{QN}-1$} \\
\hline & Gas & Liquid & Gas & Liquid & Gas & Liquid \\
\hline C1 & -0.514 & -0.538 & -0.547 & -0.541 & -0.479 & -0.542 \\
\hline $\mathrm{C} 2$ & 0.422 & 0.349 & 0.467 & 0.323 & 0.385 & 0.336 \\
\hline C3 & -0.475 & -0.502 & -0.494 & -0.555 & -0.446 & -0.509 \\
\hline $\mathrm{C} 4$ & -0.418 & -0.221 & -0.384 & -0.263 & -0.384 & -0.207 \\
\hline C5 & 1.164 & 1.182 & 1.201 & 1.217 & 1.166 & 1.259 \\
\hline C6 & -0.376 & -0.363 & -0.391 & -0.407 & -0.357 & -0.399 \\
\hline C7 & -0.692 & -0.703 & -0.726 & -0.703 & -0.671 & -0.696 \\
\hline C8 & 0.140 & 0.160 & 0.161 & 0.264 & 0.116 & -0.001 \\
\hline C9 & 0.278 & 0.232 & 0.322 & 0.235 & 0.248 & 0.296 \\
\hline C10 & -0.286 & -0.318 & -0.321 & -0.336 & -0.280 & -0.334 \\
\hline C11 & -0.288 & 0.154 & -0.217 & 0.103 & -0.325 & 0.088 \\
\hline C12 & -1.003 & -1.201 & -1.092 & -1.120 & -0.970 & -1.135 \\
\hline C13 & 0.875 & 0.696 & 0.985 & 0.624 & 0.894 & 0.720 \\
\hline C14 & -0.984 & -0.517 & -0.994 & -0.552 & -1.019 & -0.545 \\
\hline C15 & -0.271 & -0.188 & -0.317 & -0.224 & -0.252 & -0.196 \\
\hline C16 & -0.247 & -0.301 & -0.289 & -0.366 & -0.236 & -0.314 \\
\hline $\mathrm{C} 17$ & -0.388 & -0.469 & -0.387 & -0.478 & -0.386 & -0.490 \\
\hline C18 & 1.038 & 0.619 & 0.927 & 0.481 & 1.047 & 0.588 \\
\hline C19 & 0.790 & 0.767 & 0.828 & 0.744 & 0.808 & 0.831 \\
\hline $\mathrm{C} 20$ & -0.570 & -0.575 & -0.504 & -0.608 & -0.567 & -0.659 \\
\hline $\mathrm{C} 21$ & -0.430 & -0.414 & -0.464 & -0.449 & -0.412 & -0.425 \\
\hline C22 & -0.240 & -0.333 & -0.265 & -0.366 & -0.225 & -0.341 \\
\hline $\mathrm{C} 23$ & -0.376 & -0.410 & -0.383 & -0.436 & -0.372 & -0.408 \\
\hline C24 & 0.050 & -0.043 & -0.054 & -0.095 & 0.077 & -0.069 \\
\hline N1 & -0.187 & -0.217 & -0.214 & -0.309 & -0.164 & -0.200 \\
\hline $\mathrm{N} 2$ & 0.030 & 0.037 & 0.025 & -0.039 & 0.085 & 0.083 \\
\hline $\mathrm{O}$ & -0.151 & -0.230 & -0.278 & -0.457 & -0.103 & -0.211 \\
\hline S & -0.835 & -1.002 & -1.026 & -1.135 & -0.530 & -0.657 \\
\hline
\end{tabular}
index of the quantum chemical parameters with the
Table 7 Calculated Mulliken atomic charges for BTPTT using DFT at the B3LYP/++6-31G $(\mathrm{d}, \mathrm{p})$ basis set

experimental inhibition efficiency $\left(I_{\exp } \%\right)$ of the studied inhibitors. Tables 3 and 4 show the fitted equations obtained using multiple regression analyses. Table 5; Figs. 3 and 4 show that the $\mathrm{Ie}_{\mathrm{cal}} \%$ values of BCPTI and BTPTT, calculated by using Eqs. (5) and (3), agree well with the experimental results.

\section{Local molecular reactivity}

Selectivity parameters indicate the regions of a molecule that are likely to interact with a metal surface. These parameters include the Mulliken atomic charges, distribution of frontier molecular orbital and the Fukui functions [52]. An atom with the highest negative partial atomic charge interacts most strongly with a metal surface through a donor-acceptor type of interaction because it represents the site with the highest electron density. Tables 6 and 7 
Table 8 Calculated Fukui functions for BCPTI using DFT at the B3LYP/++6-31G (d, p) basis set

\begin{tabular}{|c|c|c|c|c|c|c|}
\hline \multirow[t]{2}{*}{ Atom } & \multicolumn{2}{|l|}{$\left|f^{+}\right|$} & \multicolumn{2}{|l|}{$\left|f^{-}\right|$} & \multicolumn{2}{|l|}{$|\Delta f|$} \\
\hline & Gas & Liquid & Gas & Liquid & Gas & Liquic \\
\hline $\mathrm{C} 1$ & 0.010 & 0.004 & 0.008 & 0.004 & 0.003 & 0.000 \\
\hline $\mathrm{C} 2$ & 0.035 & 0.038 & 0.094 & 0.126 & 0.059 & 0.088 \\
\hline C3 & 0.030 & 0.007 & 0.024 & 0.026 & 0.054 & 0.033 \\
\hline $\mathrm{C} 4$ & 0.060 & 0.042 & 0.024 & 0.065 & 0.036 & 0.023 \\
\hline C5 & 0.008 & 0.022 & 0.044 & 0.026 & 0.036 & 0.048 \\
\hline C6 & 0.007 & 0.005 & 0.059 & 0.029 & 0.066 & 0.033 \\
\hline C7 & 0.006 & 0.043 & 0.039 & 0.029 & 0.033 & 0.015 \\
\hline C8 & 0.036 & 0.038 & 0.054 & 0.099 & 0.089 & 0.137 \\
\hline C9 & 0.015 & 0.012 & 0.061 & 0.069 & 0.047 & 0.056 \\
\hline $\mathrm{C} 10$ & 0.056 & 0.036 & 0.140 & 0.006 & 0.083 & 0.042 \\
\hline C11 & 0.036 & 0.037 & 0.112 & 0.032 & 0.076 & 0.069 \\
\hline C12 & 0.056 & 0.005 & 0.081 & 0.022 & 0.024 & 0.026 \\
\hline C13 & 0.122 & 0.035 & 0.042 & 0.015 & 0.080 & 0.020 \\
\hline C14 & 0.095 & 0.087 & 0.045 & 0.011 & 0.141 & 0.098 \\
\hline C15 & 0.001 & 0.001 & 0.002 & 0.004 & 0.003 & 0.004 \\
\hline C16 & 0.033 & 0.049 & 0.003 & 0.007 & 0.030 & 0.042 \\
\hline C17 & 0.034 & 0.059 & 0.021 & 0.025 & 0.012 & 0.034 \\
\hline C18 & 0.030 & 0.080 & 0.012 & 0.010 & 0.018 & 0.089 \\
\hline C19 & 0.011 & 0.010 & 0.020 & 0.062 & 0.032 & 0.052 \\
\hline C20 & 0.069 & 0.058 & 0.026 & 0.038 & 0.095 & 0.020 \\
\hline $\mathrm{C} 21$ & 0.013 & 0.015 & 0.027 & 0.020 & 0.014 & 0.004 \\
\hline $\mathrm{C} 22$ & 0.016 & 0.019 & 0.030 & 0.022 & 0.014 & 0.003 \\
\hline C23 & 0.009 & 0.014 & 0.015 & 0.012 & 0.006 & 0.002 \\
\hline $\mathrm{C} 24$ & 0.072 & 0.075 & 0.041 & 0.032 & 0.031 & 0.043 \\
\hline N1 & 0.003 & 0.016 & 0.007 & 0.037 & 0.010 & 0.021 \\
\hline $\mathrm{N}$ & 0.060 & 0.047 & 0.095 & 0.098 & 0.036 & 0.051 \\
\hline N2 & 0.003 & 0.020 & 0.018 & 0.039 & 0.015 & 0.019 \\
\hline $\mathrm{O} 1$ & 0.045 & 0.023 & 0.059 & 0.059 & 0.014 & 0.036 \\
\hline $\mathrm{O} 2$ & 0.015 & 0.010 & 0.017 & 0.024 & 0.002 & 0.014 \\
\hline $\mathrm{O}$ & 0.117 & 0.188 & 0.015 & 0.029 & 0.102 & 0.159 \\
\hline
\end{tabular}

report the Mulliken atomic charges of the atoms in the anionic $\left(Q_{N+1}\right)$, neutral $\left(Q_{N}\right)$ and cationic $\left(Q_{N-1}\right)$ states of the studied compounds in both phases. $Q_{N+1}$ is an anion with an electron added to the LUMO of its neutral molecule. $Q_{N-1}$ is a cation with an electron removed from the HOMO of its neutral molecule.

The highest negative charges are on $\mathrm{C} 6$ and $\mathrm{C} 10$ atoms of the BCPTI in its gas phase and on $\mathrm{C} 10$ atom in its liquid phase. High negative charges exist on oxygen and nitrogen atoms of the BCPTI.

The highest negative charges are on $\mathrm{C} 12$ and the heteroatom S of the BTPTT in both phases. Because heteroatoms have lone pair of electrons, these lone pair of electrons could be donated to the vacant $s$ or partially filled $d$ orbital of a metal and thereby facilitate the adsorption of
Table 9 Calculated Fukui functions for BTPTT using DFT at the B3LYP/++6-31G (d, p) basis set

\begin{tabular}{|c|c|c|c|c|c|c|}
\hline \multirow[t]{2}{*}{ Atom } & \multicolumn{2}{|l|}{$\left|f^{+}\right|$} & \multicolumn{2}{|l|}{$\left|f^{-}\right|$} & \multicolumn{2}{|l|}{$|\Delta f|$} \\
\hline & Gas & Liquid & Gas & Liquid & Gas & Liquid \\
\hline $\mathrm{C} 1$ & 0.034 & 0.003 & 0.035 & 0.003 & 0.001 & 0.006 \\
\hline $\mathrm{C} 2$ & 0.045 & 0.026 & 0.037 & 0.012 & 0.009 & 0.038 \\
\hline C3 & 0.019 & 0.053 & 0.029 & 0.007 & 0.010 & 0.060 \\
\hline $\mathrm{C} 4$ & 0.034 & 0.042 & 0.034 & 0.014 & 0.068 & 0.028 \\
\hline C5 & 0.037 & 0.035 & 0.002 & 0.076 & 0.039 & 0.111 \\
\hline C6 & 0.015 & 0.045 & 0.018 & 0.036 & 0.003 & 0.081 \\
\hline C7 & 0.034 & 0.001 & 0.021 & 0.007 & 0.013 & 0.007 \\
\hline C8 & 0.020 & 0.105 & 0.024 & 0.161 & 0.003 & 0.056 \\
\hline C9 & 0.043 & 0.003 & 0.031 & 0.063 & 0.012 & 0.066 \\
\hline C10 & 0.035 & 0.018 & 0.006 & 0.016 & 0.029 & 0.034 \\
\hline C11 & 0.071 & 0.051 & 0.037 & 0.066 & 0.034 & 0.117 \\
\hline $\mathrm{C} 12$ & 0.089 & 0.081 & 0.033 & 0.066 & 0.056 & 0.147 \\
\hline $\mathrm{C} 13$ & 0.109 & 0.073 & 0.018 & 0.024 & 0.127 & 0.049 \\
\hline C14 & 0.010 & 0.035 & 0.035 & 0.028 & 0.045 & 0.062 \\
\hline C15 & 0.046 & 0.036 & 0.019 & 0.008 & 0.027 & 0.044 \\
\hline C16 & 0.042 & 0.066 & 0.011 & 0.013 & 0.031 & 0.079 \\
\hline C17 & 0.000 & 0.009 & 0.002 & 0.021 & 0.002 & 0.030 \\
\hline $\mathrm{C} 18$ & 0.111 & 0.138 & 0.009 & 0.031 & 0.102 & 0.169 \\
\hline C19 & 0.038 & 0.023 & 0.018 & 0.063 & 0.056 & 0.041 \\
\hline $\mathrm{C} 20$ & 0.066 & 0.033 & 0.002 & 0.084 & 0.068 & 0.117 \\
\hline $\mathrm{C} 21$ & 0.033 & 0.035 & 0.019 & 0.010 & 0.015 & 0.045 \\
\hline $\mathrm{C} 22$ & 0.026 & 0.034 & 0.015 & 0.009 & 0.011 & 0.043 \\
\hline $\mathrm{C} 23$ & 0.007 & 0.027 & 0.004 & 0.002 & 0.003 & 0.025 \\
\hline $\mathrm{C} 24$ & 0.104 & 0.052 & 0.027 & 0.025 & 0.078 & 0.077 \\
\hline N1 & 0.027 & 0.091 & 0.024 & 0.017 & 0.004 & 0.074 \\
\hline $\mathrm{N} 2$ & 0.006 & 0.075 & 0.055 & 0.047 & 0.049 & 0.029 \\
\hline $\mathrm{O}$ & 0.126 & 0.227 & 0.049 & 0.019 & 0.077 & 0.208 \\
\hline S & 0.191 & 0.133 & 0.305 & 0.346 & 0.114 & 0.213 \\
\hline
\end{tabular}

the inhibitor on the metal surface. BCPTI has more heteroatoms than BTPTT. Therefore, BCPTI has a higher charge density and would interact with a metal surface at more sites than BTPTT. BTPTT has the highest sites for adsorption onto a metal surface because it has the highest number of heteroatoms.

The Fukui indices permit the distinction between the reactive regions of a molecule, the nucleophilic and electrophilic behaviors of a molecule and the chemical reactivity. These functions can be given by Eqs. (6) and (7) [53]:

$f^{+}=Q_{N+1}-Q_{N}$

$f^{+}=Q_{N}-Q_{N-1}$.

The calculated values of the Fukui functions for the nonhydrogen atoms are reported in Tables 8 and 9 . 
Fig. 5 The structures of $\mathrm{Fe}-$ inhibitor complexes (using DFT/B3LYP/6-311++G (d, p))

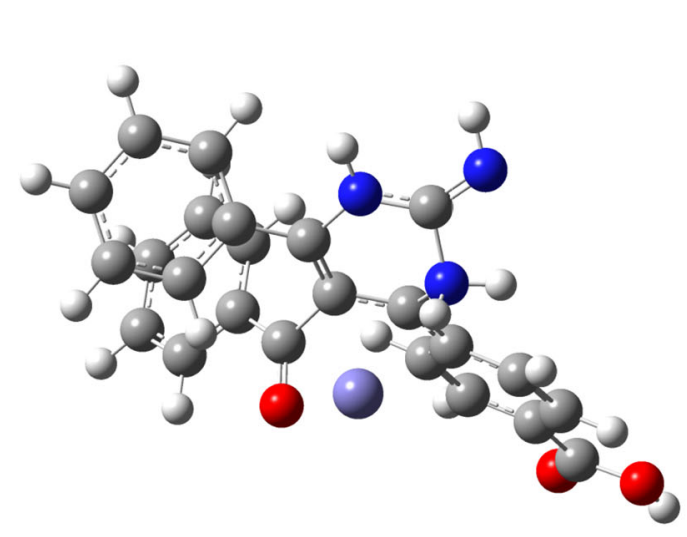

BCPTI...Fe

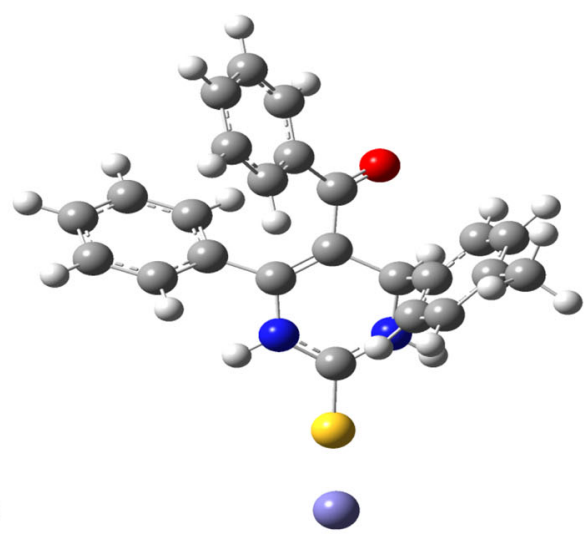

BTPTT...Fe
Table 10 The interaction energy and the energy binding between the metal and the inhibitor

\begin{tabular}{|c|c|c|c|c|c|c|c|}
\hline \multirow[t]{2}{*}{ Complex } & \multirow[t]{2}{*}{ Bond type } & \multicolumn{2}{|c|}{ Inhibitor $\cdots F e$ separation distance } & \multicolumn{2}{|c|}{$E_{\text {interaction }}(\mathrm{eV})$} & \multicolumn{2}{|c|}{$E_{\text {binding }}(\mathrm{eV})$} \\
\hline & & Gas & Liquid & Gas & Liquid & Gas & Liquid \\
\hline \multirow[t]{4}{*}{ BCPТI $\cdots \mathrm{Fe}$} & $\mathrm{O} \cdots \mathrm{Fe}$ & 1.882 & 1.902 & -3.319 & -3.259 & 3.319 & 3.259 \\
\hline & $\mathrm{C} 10 \cdots \mathrm{Fe}$ & 3.784 & 3.813 & & & & \\
\hline & $\mathrm{C} 8 \cdots \mathrm{Fe}$ & 1.987 & 1.941 & & & & \\
\hline & $\mathrm{C} 6 \cdots \mathrm{Fe}$ & 2.106 & 2.126 & & & & \\
\hline ВТРТТ $\cdots F e$ & $\mathrm{~S} \cdots \mathrm{Fe}$ & 1.548 & 1.694 & 1.074 & 1.198 & -1.074 & -1.198 \\
\hline
\end{tabular}

The maximum of $\mathrm{f}^{+}$corresponds to reactivity with respect to nucleophilic attack and the maximum of $f^{-}$ shows the preferred site for adsorption of electrophilic agents. For BCPTI, the highest $f^{+}$is associated with $\mathrm{C} 13$ and $\mathrm{O}$ atoms in gas phase and $\mathrm{O}$ atom in liquid phase and the highest $f^{-}$occurs at $\mathrm{C} 10$ and $\mathrm{C} 11$ atoms in gas phase and at $\mathrm{C} 2$ and $\mathrm{C} 8$ atoms in liquid phase. The BTPTT sites for nucleophilic attack are the $\mathrm{S}$ atoms in gas phase and $\mathrm{O}$ atoms in liquid phases. However, the BTPTT sites for electrophilic attack are only the $\mathrm{S}$ atoms in both gas and liquid phases.

\section{The adsorption of inhibitors on austenitic stainless steel}

Iron is the major element of the austenitic stainless steel. Therefore, the iron interaction with the inhibitor molecules should be investigated [26-28]. The binding capability of a metal on the inhibitors depends strongly on the electronic charge of the active site. The Mulliken atomic charges, distribution of frontier molecular orbital and the Fukui functions show that iron atom is located among $\mathrm{C} 6, \mathrm{C} 8$, $\mathrm{C} 10$ and $\mathrm{O}$ atoms of BCPTI molecule whereas in BTPTT molecule, the iron atom Therefore, BCPTI and BTPTT were allowed to interact with the Fe metal at the C6, C8, $\mathrm{C} 10$ and the $\mathrm{S}$ atom. The interaction energy between the inhibitor and the metal was then estimated as the difference between the energy of the complex $\left(E_{\mathrm{Fe}-\mathrm{X}}\right)$ and the sum of the energy of the isolated inhibitor and isolated $\mathrm{Fe}$ atom $\left(E_{\mathrm{X}}+E_{\mathrm{Fe}}\right)$ resulting in the equation: $E_{\text {interaction }}=$ $E_{\mathrm{Fe}-\mathrm{X}}-\left(E_{\mathrm{X}}+E_{\mathrm{Fe}}\right)$. The binding energy of the inhibitor molecule is the negative value of interaction energy [54].

The optimized inhibitor...Fe complexes are shown in Fig. 5. The inhibitor $\cdots$ Fe separation distance, the calculated interaction and binding energy are reported in Table 10. The strong adsorption between the inhibitor molecules and the iron can be estimated as the larger negative values of interaction energy [55]. Table 10 shows that BCPTI has the highest interaction energy and therefore has the highest inhibition efficiency. From the theoretical point of view, the higher magnitude of BCPTI binding energy suggests a more stable adsorption and a higher inhibition efficiency system.

\section{Conclusions}

Quantum chemical calculations based on density functional theory method were performed on two pyrimidine derivatives which may be used as corrosion inhibitors for austenitic stainless steel. The quantum chemical properties of the two pyrimidine derivatives that are most relevant to 
their potential action as corrosion inhibitors were calculated in gas and liquid phases for comparison purposes. Our results indicate computational data for liquid phase represent the experimental results better than the data for gas phase. The quantum chemical parameters of the inhibitors are different in gas and liquid phases and some of the same type parameters obtained by orbital method are different from those obtained by energy method. We have not been able to establish relationships between some of quantum chemical parameters, e.g., molecular softness and energy gap.

In this study, the corrosion inhibition capabilities of the BCPTI and BTPTT were investigated. We have made the following conclusions:

1. BTPTT has a smaller energy gap than BCPTI in liquid phase and therefore it is a better inhibitor.

2. Based on global softness, hardness and chemical potential obtained by energy method but excluding calculations obtained by orbital method, BCPTI is a better inhibitor than BTPTT in both gas and liquid phases.

3. Based on dipole moment and molecular mass, BCPTI is a better inhibitor than BTPTT in both gas and liquid phases.

4. An equation has been proposed to calculate the inhibition efficiency. The regression analyses fitted the Caliskan et al. experimental data well and the calculated inhibition efficiencies of the studied compounds were found to be close to their experimental corrosion inhibition efficiencies.

5. The adsorption of the studied compounds onto the steel surface shows that BCPTI inhibitor has a higher magnitude of binding energy than BTPTT.

6. Overall, BCPTI may be a better inhibitor than BTPTT.

Acknowledgments This work was supported by Graduate University of Advanced Technology and Research Center for Science, High Technology \& Environmental Science, Kerman.

Open Access This article is distributed under the terms of the Creative Commons Attribution 4.0 International License (http://creative commons.org/licenses/by/4.0/), which permits unrestricted use, distribution, and reproduction in any medium, provided you give appropriate credit to the original author(s) and the source, provide a link to the Creative Commons license, and indicate if changes were made.

\section{References}

1. Elayyachy M, Hammouti B, El Idrissi A (2005) New telechelic compounds as corrosion inhibitors for steel in $1 \mathrm{M} \mathrm{HCl}$. Appl Surf Sci 249:176-182

2. Bouklah M, Hammouti B, Lagrenée M, Bentiss F (2006) Thermodynamic properties of 2,5-bis(4-methoxyphenyl)-1,3,4-oxadiazole as a corrosion inhibitor for mild steel in normal sulfuric acid medium. Corros Sci 48:2831-2842
3. Khatak HS, Baldev R (2002) Corrosion of austenitic stainless steels: mechanism, mitigation and monitoring, ASM International, Narosa Publishing House

4. Marshall P (1984) Austenitic stainless steels: microstructure and mechanical properties. Elsevier Applied Science Publishers Ltd, New York

5. Truman JE, Pirt KR (1997) A note on the corrosion produced under deposits of chlorides on austenitic stainless steel. Corros Sci 17:71-74

6. Craig DB (1995) Selection guidelines for corrosion resistant alloys in the oil and gas industry. NiDI Technical Series No. 10 073, Toronto, Ontario, Canada

7. Emregül KC, Atakol O (2003) Corrosion inhibition of mild steel with Schiff base compounds in $1 \mathrm{M} \mathrm{HCl}$. Mater Chem Phys 82:188-193

8. Elayyachy M, El Idrissi A, Hammouti B (2006) New thio-compounds as corrosion inhibitor for steel in $1 \mathrm{M} \mathrm{HCl}$. Corros Sci 48:2470-2479

9. Fouda AS, Ellithy AS (2009) Inhibition effect of 4-phenylthiazole derivatives on corrosion of $304 \mathrm{~L}$ stainless steel in $\mathrm{HCl}$ solution. Corros Sci 51:868-875

10. Refaey SAM, Taha F, Abd El-Malak AM (2006) Corrosion and Inhibition of $316 \mathrm{~L}$ stainless steel in neutral medium by 2 -mercaptobenzimidazole. Int J Electrochem Sci 1:80-91

11. Selvakumar P, Balanaga Karthik B, Thangavelu C (2013) Corrosion inhibition study of stainless steel in acidic medium-an overview. Res J Chem Sci 3:87-95

12. Adnani ZE, Mcharfi M, Sfaira M, Benzakour M, Benjelloun AT, Touhami ME (2013) DFT theoretical study of 7-R3methylquinoxalin-2(1H)-thiones $(\mathrm{R}=\mathrm{H} ; \mathrm{CH} 3 ; \mathrm{Cl})$ as corrosion inhibitors. Corros Sci 68:223-230

13. Kabanda MM, Murulana LC, Ozcan M, Karadag F, Dehri I, Obot IB, Ebenso EE (2010) Quantum chemical studies on the corrosion inhibition of mild steel by some triazoles and benzimidazole derivatives in acidic medium. Int J Electrochem Sci 7:5035-5056

14. Khaled KF (2008) Molecular simulation, quantum chemical calculations and electrochemical studies for inhibition of mild steel by triazoles. Electrochim Acta 53:3484-3492

15. Xia S, Qiu M, Yu L, Liu F, Zhao H (2008) Molecular dynamics and density functional theory study on relationship between structure of imidazoline derivatives and inhibition performance. Corros Sci 50:2021-2029

16. Elmsellem H, Aouniti A, Khoutoul M, Chetouani A, Hammouti B, Benchat N, Touzani R, Elazzouzi M (2014) Theoretical approach to the corrosion inhibition efficiency of some pyrimidine derivatives using DFT method of mild steel in $\mathrm{HCl}$ solution. J Chem Pharm Res 6(4):1216-1224

17. Udhayakala P, Rajendiran TV (2015) A theoretical evaluation on benzothiazole derivatives as corrosion inhibitors on mild steel. Der Pharma Chem 7(1):92-99

18. Ismaily AK, El Hajjaji F, Azaroual MA, Taleb M, Chetouani A, Hammouti B, Abrigach F, Khoutoul M, Abboud Y, Aouniti A, Touzani R (2014) Experimental and quantum chemical studies on corrosion inhibition performance of pyrazolic derivatives for mild steel in hydrochloric acid medium, correlation between electronic structure and inhibition efficiency. J Chem Pharm Res 6(7):63-81

19. Yadav M, Kumar S, Kumari N, Bahadur I, Ebenso EE (2015) Experimental and theoretical studies on corrosion inhibition effect of synthesized benzothiazole derivatives on mild steel in $15 \% \mathrm{HCl}$ solution. Int J Electrochem Sci 10:602-624

20. Zarrouk A, Hammouti B, Lakhlifi T, Traisnel M, Vezin H, Bentiss F (2015) New 1H-pyrrole-2,5-dione derivatives as efficient organic inhibitors of carbon steel corrosion in hydrochloric acid medium: electrochemical, XPS and DFT studies. Corros Sci 90:572-584 
21. Murulana LC, Kabandabc MM, Ebenso EE (2015) Experimental and theoretical studies on the corrosion inhibition of mild steel by some sulphonamides in aqueous $\mathrm{HCl}$. RSC Adv 5:28743-28761

22. Saha SK, Dutta A, Ghosh P, Sukulc D, Banerjee P (2015) Adsorption and corrosion inhibition effect of Schiff base molecules on the mild steel surface in $1 \mathrm{M} \mathrm{HCl}$ medium: a combined experimental and theoretical approach. Phys Chem Chem Phys 17(8):5679-5690

23. Kayadibi F, Sagdinc SG, Kara YS (2015) Density functional theory studies on the corrosion inhibition of benzoin, benzil, benzoin-(4-phenylthiosemicarbazone) and benzil-(4-phenylthiosemicarbazone) of mild steel in hydrochloric acid. Prot Metals Phys Chem Surf 51(1):143-154

24. Odozi NW, Babalola JO, Ituen EB, Eseola AO (2015) Imidazole derivative as novel effective inhibitor of mild steel corrosion in aqueous sulphuric acid. Am J Phys Chem 4(1-1):1-9

25. Radillaa J, Negrón-Silvaa GE, Palomar-Pardavéb M, RomeroRomob M, Galvánc M (2013) DFT study of the adsorption of the

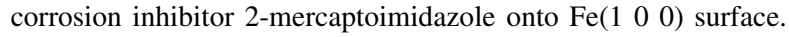
Electrochim Acta 112(1):577-586

26. Ebenso EE, Kabanda MM, Arslan T, Saracoglu M, Kandemirli F, Murulana LC, Singh AK, Shukla SK, Hammouti B, Khaled KF, Quraishi MA, Obot IB, Eddy NO (2012) Quantum chemical investigations on quinoline derivatives as effective corrosion inhibitors for mild steel in acidic medium. Int J Electrochem Sci 7:5643-5676

27. Kabanda MM, Murulana LC, Ebenso EE (2012) Theoretical studies on phenazine and related compounds as corrosion inhibitors for mild steel in sulphuric acid medium. Int J Electrochem Sci 7:7179-7205

28. Kabanda MM, Ebenso EE (2012) Density functional theory and quantitative structure-activity relationship studies of some quinoxaline derivatives as potential corrosion inhibitors for copper in acidic medium. Int J Electrochem Sci 7:8713-8733

29. Caliskan N, Akbas E (2012) Corrosion inhibition of austenitic stainless steel by some pyrimidine compounds in hydrochloric acid. Mater Corros 3:231-237

30. Frisch MJ, Trucks GW, Schlegel HB, Scuseria GE, Robb MA, Cheeseman JR, Scalmani G, Barone V, Mennucci B, Petersson GA, Nakatsuji H, Caricato M, Li X, Hratchian HP, Izmaylov AF, Bloino J, Zheng G, Sonnenberg JL, Hada M, Ehara M, Toyota K, Fukuda R, Hasegawa J, Ishida M, Nakajima T, Honda Y, Kitao O, Nakai H, Vreven T, Montgomery JA, Jr, Peralta JE, Ogliaro F, Bearpark M, Heyd JJ, Brothers E, Kudin KN, Staroverov VN, Keith T, Kobayashi R, Normand J, Raghavachari K, Rendell A, Burant JC, Iyengar SS, Tomasi J, Cossi M, Rega N, Millam JM, Klene M, Knox JE, Cross JB, Bakken V, Adamo C, Jaramillo J, Gomperts R, Stratmann RE, Yazyev O, Austin AJ, Cammi R, Pomelli C, Ochterski JW, Martin RL, Morokuma K, Zakrzewski VG,Voth GA, Salvador P, Dannenberg JJ, Dapprich S, Daniels AD, Farkas O, Foresman JB, Ortiz JV, Cioslowski J, Fox DJ (2010) Gaussian, Inc., Wallingford

31. Li W, Zhao X, Liu F, Deng J, Hou B (2009) Investigation on the corrosion inhibitive effect of $2 \mathrm{H}$-pyrazole-triazole derivatives in acidic solution. Mater Corros 60:287-293

32. Hasanov R, Sadikoglu M, Bilgic S (2007) Electrochemical and quantum chemical studies of some Schiff bases on the corrosion of steel in $\mathrm{H}_{2} \mathrm{SO}_{4}$ solution. Appl Surf Sci 253:3913-3921

33. Pearson RG (1988) Chemical hardness and bond dissociation energies. J Am Chem Soc 110:7684-7690

34. Masoud MS, Awad KM, Shaker MA, El-Tahawy MMT (2010) The role of structural chemistry in the inhibitive performance of some aminopyrimidines on the corrosion of steel. Corros Sci 52:2387-2396
35. Zhan CG, Nichols JA, Dixon DA (2003) Ionization potential, electron affinity, electronegativity, hardness, and electron excitation energy: molecular properties from density functional theory orbital energies. J Phys Chem A 107:4184-4195

36. Parr RG, Pearson RG (1983) Absolute hardness: companion parameter to absolute electronegativity. J Am Chem Soc 105:7512-7516

37. Yang W, Parr RG (1985) Hardness, softness, and the Fukui function in the electronic theory of metals and catalysis. Proc Natl Acad Sci 82:6723-6726

38. Parr RG, Szentpaly LV, Liu S (1999) Electrophilicity index. J Am Chem Soc 121:1922-1924

39. Gázquez JL, Cedillo A, Vela A (2007) Electrodonating and electroaccepting powers. J Phys Chem A 111:1966-1970

40. Chattaraj PK, Giri S, Duley S (2011) Update 2 of: electrophilicity index. Chem Rev 111:PR43-PR75

41. Gómez B, Likhanova NV, Domínguez-Aguilar MA, MartínezPalou R, Vela A, Gázquez JL (2006) Quantum chemical study of the inhibitive properties of 2-pyridyl-azoles. J Phys Chem B 110:8928-8934

42. Lece HD, Emregül KC, Atakol O (2008) Difference in the inhibitive effect of some Schiff base compounds containing oxygen, nitrogen and sulfur donors. Corros Sci 50:1460-1468

43. Nataraja SE, Venkatesha TV, Tandon TV, Shylesha BS (2011) Quantum chemical and experimental characterization of the effect of ziprasidone on the corrosion inhibition of steel in acid media. Corros Sci 53:41094117

44. Li X, Deng S, Fu H, Li T (2009) Adsorption and inhibition effect of 6-benzylaminopurine on cold rolled steel in $1.0 \mathrm{M} \mathrm{HCl}$. Electrochim Acta 54:4089-4098

45. Cancès E, Mennucic B, Tomasi J (1997) A new integral equation formalism for the polarizable continuum model: theoretical background and applications to isotropic and anisotropic dielectrics. J Chem Phys 107:3032-3041

46. El- Ashry ES, Senior SA (2011) QSAR of lauric hydrazide and its salts as corrosion inhibitors by using the quantum chemical and topological descriptors. Corros Sci 53:1025-1034

47. Chattaraj PK, Chakraborty A, Giri S (2009) Net electrophilicity. J Phys Chem A 113:10068-10071

48. Sastri VS, Perumareddi JR (1997) Molecular orbital theoretical studies of some organic corrosion inhibitors. Corrosion 53:617-622

49. Musa AY, Kadhum AAH, Mohamad AB, Rahoma AAB, Mesmari $\mathrm{H}$ (2010) Electrochemical and quantum chemical calculations on 4,4-dimethyloxazolidine-2-thione as inhibitor for mild steel corrosion in hydrochloric acid. J Mol Struct 969:233-237

50. Weiler-Feilchenfeld H, Pullman A, Berthod H, Giessner-Prettre C (1970) Experimental and quantum-chemical studies of the dipole moments of quinoline and indole. J Mol Struct 6:297-304

51. Jensen F (1999) Introduction to computational chemistry. Wiley, Chichester

52. Gece G, Bilgic S (2010) A theoretical study on the inhibition efficiencies of some amino acids as corrosion inhibitors of nickel. Corros Sci 52:3435-3443

53. Yang Y, Mortier WJ (1986) The use of global and local molecular parameters for the analysis of the gas-phase basicity of amines. J Am Chem Soc 108:5708-5711

54. Al-Mobarak NA, Khaled KF, Hamed MNH, Abdel-Azim KM, Abdelshafi NS (2010) Corrosion inhibition of copper in chloride media by 2-mercapto-4-( $p$-methoxyphenyl)-6-oxo-1,6-dihydropyrimidine-5-carbonitrile: electrochemical and theoretical study. Arab J Chem 3:233-242

55. Musa AY, Khadom AA, Kadhum AAH, Mohamad AB, Takriff MS (2010) Experimental and theoretical study on the inhibition performance of triazole compounds for mild steel corrosion. Corros Sci 52:3331-3340 